\title{
Carta aberta na escola: um olhar a partir da composição do gênero e da progressão tópica
}

\author{
Huanna Sperb Ross" \\ Aline Rubiane Arnemann** \\ Monize Pereira Albiero***
}

\section{Resumo}

Neste artigo, apresentamos uma reflexão sobre como o trabalho com a composição do gênero carta aberta e com a progressão tópica pode contribuir para práticas de produção textual escolares, pois consideramos essa articulação mais uma possibilidade de subsidiar o processo de escrita argumentativa. Como corpus de análise, selecionamos duas versões de uma carta aberta produzida por um estudante de terceiro ano de Ensino Médio. Para tanto, estabelecemos dois passos analíticos: $1^{\circ}$ ) estrutura composicional do gênero carta aberta; $2^{\circ}$ ) disposição das pirâmides tópicas. Como resultado, na última versão analisada, observamos que, em relação à estrutura, houve avanços no que diz respeito ao título e à assinatura do remetente. Quanto à progressão tópica, constatamos que os tópicos foram parcialmente desenvolvidos, restringindo a construção argumentativa. Assim, esperamos que essa reflexão possa embasar práticas pedagógicas e auxiliar no avanço da escrita escolar, de modo que estratégias argumentativas sejam suficientemente exploradas.

Palavras-chave: Carta aberta; produção textual; progressão tópica.
* Graduada em Letras - Português / Inglês pelo Centro Universitário Franciscano - UFN (2014). Mestre em Estudos Linguísticos pela Universidade Federal de Santa Maria - UFSM (2018). Durante a graduação, foi bolsista PIBID / CAPES / UFN atuando no subprojeto Letras / Inglês (2012-2015). Atualmente, é professora de Língua Inglesa e Língua Portuguesa (6oa ao 9o ano) na Escola Municipal de Ensino Fundamental Alfredo Lenhardt, Itaara e ministra aulas particulares de Língua Portuguesa e Redação no Super Reforço Escolar. E-mail: huannaross@hotmail.com

** Graduada em Letras Licenciatura Habilitação Português e Literaturas da Língua Portuguesa (UFSM/2014), mestre em Estudos Linguísticos (UFSM/2017). Atualmente, é doutoranda em Estudos Linguísticos, investigando o critério de informatividade em sua pesquisa. Seus estudos estão situados na Linguística do Texto, envolvendo, também, Sociointeracionismo e Pesquisa-ação e professora substituta do Departamento de Metodologia do Ensino (UFSM). É integrante do Grupo de Estudos em Linguística do Texto e Ensino (GELTE). E-mail: arnemannaline@gmail.com

**** Professora de Língua Portuguesa, nos anos finais do Ensino Fundamental, na Rede Privada de Ensino.Mestranda em Estudos Linguísticos, na linha de pesquisa Linguagem e Interação, no Programa de Pós-Graduação em Letras (PPGL) da Universidade Federal de Santa Maria (UFSM). Integrante do Grupos de Estudos em Linguística do Texto e Ensino (GELTE). Especialista em Gestão e Docência no Ensino Superior pela Universidade Luterana do Brasil (ULBRA) - Polo EAD de Santa Maria. Licenciada em Letras - Português e Literaturas - pela UFSM. Bacharela em Direito pela ULBRA - Campus Santa Maria. E-mail: monizealbiero@hotmail.com

Data de submissão: abr. 2021 - Data de aceite: jul. 2021 http://dx.doi.org/10.5335/rdes.v17i2.12621 


\section{Introdução}

O ensino de Língua Portuguesa (LP), no Brasil atual, busca adequar-se à perspectiva dialógica (BAKHTIN, 2011) de trabalho com gêneros textuais. Realizamos essa afirmação, pois a Base Nacional Comum Curricular (BNCC) dispõe o ensino de LP sob esse viés. Nesse sentido, entendemos a necessidade de compartilhar possibilidades, atualizações e reflexões que envolvam a interlocução do gênero textual com a sala de aula.

No presente artigo, objetivamos refletir sobre como o trabalho com a composição do gênero carta aberta e com a progressão tópica pode contribuir para práticas de produção textual no âmbito escolar. Para tanto, selecionamos, como nosso corpus de análise, duas versões de uma produção textual, do gênero em questão, produzida por um estudante - nominado participante discente 16 (PD16).

Em razão disso, este artigo, além desta seção, possui outras quatro: referencial teórico, referencial metodológico, análise e discussão, bem como conclusão. O referencial teórico está subdividido em "gênero carta aberta" e "progressão tópica". De mesmo modo, o referencial metodológico, está organizado em "contexto de produção da carta aberta em uma pesquisa de doutorado", "corpus de análise" e "passos de análise". Já a análise está organizada em dois passos: "estrutura composicional do gênero carta aberta" e "disposição das pirâmides tópicas". Estes resultam na "discussão sobre os dois objetos de análise". Para encerrar, registramos as reflexões decorrentes de nossa análise.

\section{Gênero carta aberta}

Bakhtin $(2014,2011)$ trouxe duas grandes contribuições aos estudos de linguagem com as postulações acerca do dialogismo e dos gêneros do discurso, respectivamente. O teórico (2014) dispõe que a palavra é o elo que efetiva a interação humana, o que caracteriza como interação verbal. As palavras são proferidas por alguém e se destinam a alguém, configurando, assim, o caráter dialógico da língua. Dessa forma, a interação verbal se realiza por meio de enunciações que, em modo organizado e sistematizado, constituem os gêneros do discurso. Esses são tão diversos e infinitos quanto as ações humanas e são classificados pelo estudioso (2011) em gêneros primários (mais simples) e gêneros secundários (complexos). Desse modo, o referido autor inaugura os estudos sobre gêneros e, a sua luz, nascem vertentes, dentre elas, a de Dolz e Schneuwly (2004).

Sob esse contexto, Dolz e Schneuwly (2004) - pautados na concepção bakhtiniana - apresentam relevantes contribuições referentes ao trabalho com os 
gêneros textuais (orais e escritos) em sala de aula, sendo referência em documentos oficiais da educação brasileira. Os teóricos mencionados caracterizam o gênero como um "(mega)instrumento para agir em situações de linguagem" (DOLZ, SCHNEUWLY, 2004, p. 44). Seguindo essa abordagem, os autores expõem que:

todo gênero se define por três dimensões essenciais: 1) os conteúdos que são (que se tornam) dizíveis por meio dele; 2 ) a estrutura (comunicativa) particular dos textos pertencentes ao gênero; 3 ) as configurações específicas das unidades de linguagem, que são sobretudo traços da posição enunciativa do enunciador, e os conjuntos particulares de sequências textuais e de tipos discursivos que formam sua estrutura (DOLZ e SCHNEUWLY, 2004, p. 44).

Além dessas dimensões, que podem variar de acordo com o gênero, os estudiosos em comento organizam um agrupamento de gêneros: grupo do narrar, do relatar, do argumentar, do expor e do descrever ações. Nesse prisma, situamos o trabalho com a carta aberta no grupo do argumentar, que, consoante Dolz e Schneuwly (2004, p.52), tem como capacidade de linguagem dominante a "sustentação, refutação e negociação de tomadas de posição", explorando o domínio social de comunicação voltado à "discussão de problemas sociais controversos". Ademais, ressaltamos que, por ser uma "carta que se dirige publicamente a alguém através dos órgãos de imprensa" (COSTA, 2014, p. 63), ela proporciona o desenvolvimento da sustentação de um posicionamento.
Outrossim, Dolz e Schneuwly (2004) estabelecem um ponto de encontro - efetivado por meio dos gêneros - entre as práticas sociais e os objetos de ensino. Nesse contexto, para explorar a carta aberta em sala de aula, embasamo-nos nas especificidades e estrutura composicional do gênero, elencadas por Cristiane Fuzer, COPERVES (2014), no material de preparação para o vestibular seriado da Universidade Federal de Santa Maria (UFSM) - edição de 2016. Quanto a isso, vejamos, a seguir, os Quadro1 e 2.

Quadro 1 - Especificidades da carta aberta

\begin{tabular}{|c|c|}
\hline Especificidades & Comentários \\
\hline $\begin{array}{l}\text { Como pode ser } \\
\text { definido(a)? }\end{array}$ & $\begin{array}{l}\text { "Texto por meio do qual um ci- } \\
\text { dadão ou grupo dirige-se, publi- } \\
\text { camente, a um interlocutor espe- } \\
\text { cífico ou entidade ou população } \\
\text { diretamente envolvido(s) em si- } \\
\text { tuação ou assunto controverso, } \\
\text { de interesse coletivo." (COPER- } \\
\text { VES, 2014). }\end{array}$ \\
\hline $\begin{array}{l}\text { Que conteúdo } \\
\text { temático é } \\
\text { abordado? }\end{array}$ & $\begin{array}{l}\text { Assuntos originários de fatos } \\
\text { publicados, de interesse de uma } \\
\text { coletividade: } \\
\text { Tema: Carta aberta aos jovens } \\
\text { santa-marienses manifestando a } \\
\text { importância ou não de se torna- } \\
\text { rem doadores de sangue. }\end{array}$ \\
\hline $\begin{array}{l}\text { Qual o } \\
\text { propósito? }\end{array}$ & $\begin{array}{l}\text { Tornar público um objetivo, aler- } \\
\text { ta, reinvindicação, opinião, re- } \\
\text { presentativo de uma comunida- } \\
\text { de. (COPERVES, 2014). }\end{array}$ \\
\hline Quem produz? & $\begin{array}{l}\text { Um autor, mais de um autor ou } \\
\text { um autor em nome de um grupo } \\
\text { (COPERVES, 2014). }\end{array}$ \\
\hline $\begin{array}{l}\text { Qual é o } \\
\text { destinatário? }\end{array}$ & $\begin{array}{l}\text { Um indivíduo ou uma coletivida- } \\
\text { de (COPERVES, 2014). }\end{array}$ \\
\hline $\begin{array}{l}\text { Qual é o meio de } \\
\text { circulação? }\end{array}$ & $\begin{array}{l}\text { Murais (escolas e entidades) sí- } \\
\text { tios eletrônicos (blogs, revistas, } \\
\text { redes sociais) (COPERVES, } \\
\text { 2014). }\end{array}$ \\
\hline
\end{tabular}

Fonte: Adaptado de Arnemann (2020, p.141-142). 
Quadro 2 - Estrutura composicional da carta aberta

\begin{tabular}{|l|l|}
\hline \multicolumn{1}{|c|}{$\begin{array}{c}\text { Estrutura } \\
\text { composicional }\end{array}$} & \multicolumn{1}{|c|}{ Comentários } \\
\hline Título & $\begin{array}{l}\text { Título (menção ao gênero e ao } \\
\text { destinatário); }\end{array}$ \\
\hline Introdução & $\begin{array}{l}\text { Motivo da manifestação (apre- } \\
\text { sentação de problema de inte- } \\
\text { resse coletivo); }\end{array}$ \\
\hline Desenvolvimento & $\begin{array}{l}\text { Argumentação que sustenta } \\
\text { o ponto de vista (uso de argu- } \\
\text { mentos para defender o ponto } \\
\text { de vista por meio de estratégias } \\
\text { argumentativas); }\end{array}$ \\
\hline Conclusão & $\begin{array}{l}\text { Conclusão (retomada sobre a } \\
\text { discussão na tentativa de con- } \\
\text { vencer o destinatário); }\end{array}$ \\
\hline Após a conclusão & Remetente (assinatura); \\
\hline $\begin{array}{l}\text { Ao longo de todo o } \\
\text { texto. }\end{array}$ & Explicitação do destinatário. \\
\hline
\end{tabular}

Fonte: Organizado pelas autoras, com base em COPERVES (2014) e Arnemann (2020)

Dessa maneira, situadas nos estudos genebrinos de gêneros textuais e apoiadas em Cristiane Fuzer, COPERVES (2014), configuramos uma possibilidade para realizar o ensino da carta aberta em sala de aula. Essa possibilidade prevê o trabalho em conjunto com a progressão tópica.

\section{Progressão tópica}

A progressão tópica diz respeito à maneira como um determinado tópico é organizado e desenvolvido ao longo de uma produção textual, seja ela escrita ou oral. A partir disso, o tema principal, também chamado de tópico discursivo, é subdividido em diferentes segmentos tópicos, os quais, direta ou indiretamente, estão relacionados a ele, segundo aponta Koch (2014).

No que se refere ao tópico discursivo, apresentamos as duas propriedades que o definem enquanto porção textual, conforme asseveram os pesquisadores integrantes do Projeto Gramática do Português Falado (KOCH, 2014). De acordo com Jubran (2015, p. 87), cujo foco de pesquisa recai sobre os textos orais, o tópico discursivo manifesta-se "mediante enunciados formulados pelos interlocutores a respeito de um conjunto de referentes, concernentes entre si e em relevância num determinado ponto da mensagem". Esses aspectos caracterizam a primeira propriedade, denominada centração, a qual abrange três traços:

Quadro 3 - Traços da propriedade de centração

\begin{tabular}{|l|l|}
\hline \multicolumn{1}{|c|}{ Traço } & \multicolumn{1}{c|}{ Definição } \\
\hline Concernência & $\begin{array}{l}\text { Relaçântica entre os enunciados } \\
\text { semânterdependência } \\
\text { - implicativa, associativa, exem- } \\
\text { plificativa ou de qualquer outra } \\
\text { ordem - pela qual se dá sua in- } \\
\text { serção num conjunto de referen- } \\
\text { tes explícitos ou inferíveis que se } \\
\text { encontram ativados em determi- } \\
\text { nado momento do discurso. }\end{array}$ \\
\hline Relevância & $\begin{array}{l}\text { Proeminência desse conjunto } \\
\text { de referentes em determinado } \\
\text { segmento textual, em virtude da } \\
\text { posição focal assumida pelos } \\
\text { seus elementos. }\end{array}$ \\
\hline $\begin{array}{l}\text { Pontualização ou } \\
\text { delimitabilidade }\end{array}$ & $\begin{array}{l}\text { Possibilidade de localização des- } \\
\text { se conjunto tido, em dado mo- } \\
\text { mento, como focal, em determi- } \\
\text { nado ponto do texto, através de } \\
\text { marcas linguístico-discursivas. }\end{array}$ \\
\hline
\end{tabular}

Fonte: Organizado pelas autoras a partir de Koch $(2014$, p. 137) 
Compreendemos que tal propriedade se refere não apenas à manutenção do conteúdo textual, como também confere “à categoria de tópico discursivo critérios para o reconhecimento do estatuto tópico de um fragmento textual" (JUBRAN, 2015 , p. 87). Não nos deteremos, no entanto, a essa propriedade, haja vista não ser nosso foco de análise.

A segunda propriedade tópica, chamada organicidade, caracteriza-se pelas relações de interdependência entre supertópicos e subtópicos, manifestadas na produção textual, simultaneamente, em dois planos: hierárquico e linear. Nas palavras de Jubran:

a. no plano hierárquico, conforme as dependências de superordenação e subordenação entre tópicos que se implicam pelo grau de abrangência do assunto;

b. no plano linear, de acordo com as articulações intertópicas em termos de adjacência ou interposições de tópicos diferentes na linha do texto. (JUBRAN, 2015, p. 90)
O plano hierárquico é organizado verticalmente de acordo com o nível de abrangência do tema em pauta. Conforme postula Jubran (2015), é possível dispor os tópicos em camadas organizacionais que vão de um tópico amplo a um mais restrito, constituído por "tópicos mínimos", denominados assim em virtude do seu "maior grau de particularização do assunto em relevância" (JUBRAN, 2015, p. 90).

O tópico mais abrangente é chamado de supertópico (ST), ao passo que o mais particularizado, de subtópico (SbT). Entretanto, ressaltamos que o "SbT de um ST superior a ele passa a ser um ST em relação aos tópicos que o integram (SbT)" (JUBRAN, 2015, p. 91-92). Tal relação de interdependência entre o ST e seu respectivo $\mathrm{SbT}$ configura o denominado quadro tópico (QT), como podemos observar na Figura 1:

Figura 1 - Modelo de pirâmide tópica

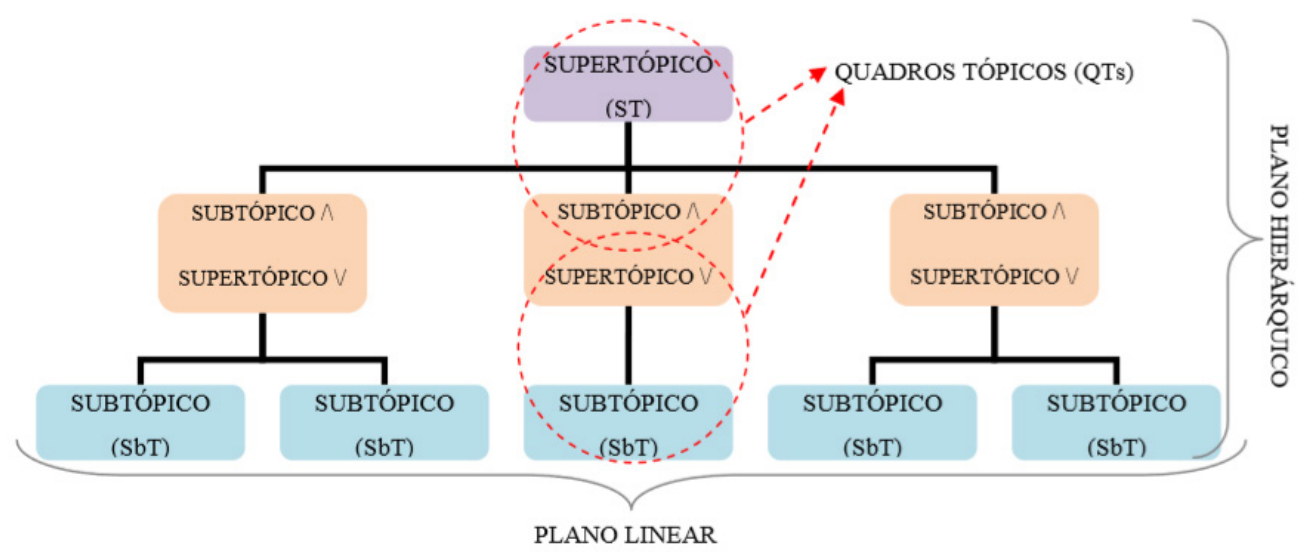

Fonte: Machado (2018, p. 78) 
Já o plano linear corresponde, em conformidade com Jubran (2015, p. 92), às "relações que se estabelecem entre tópicos", os quais se encontram, na pirâmide tópica, em um mesmo nível hierárquico, conforme podemos constatar na figura apresentada anteriormente. Também, esse plano, ainda, é caracterizado a partir de dois fenômenos básicos: continuidade e descontinuidade.

A continuidade diz respeito, nas palavras de Jubran (2015, p. 92), à “organização sequencial dos segmentos tópicos, de forma que a abertura de um apenas se dá após o fechamento de outro, precedente". Para tanto, a introdução de um novo tema ocorre somente quando não há mais possibilidades de desenvolvimento do tópico anterior. Em contrapartida, a descontinuidade "decorre de uma perturbação da sequencialidade linear" (JUBRAN, 2015, p. 94), ou seja:

a. pela suspensão definitiva de um tópico, quando um novo tópico provoca o seu corte, ocasionando uma ruptura caracterizada pelo não retorno do interrompido;

b. pela cisão de um tópico em partes, que se apresentam de forma não adjacente na linearidade do texto, em decorrência da intercalação, no seu interior, de outro(s) tópico(s);

c. pela expansão posterior de um tópico apenas anunciado anteriormente. (JUBRAN, 2015, p. 95).

Isso posto, entendemos que, para a constituição de um texto coerente, é necessário que haja continuidade dos tópicos levantados, isto é, que não ocor- ram rupturas definitivas ou interrupções em excesso, que podem vir a prejudicar o sentido do texto e a compreensão do leitor. Segundo Koch (2015, p. 161), para que haja inserções e digressões, é preciso "algum tipo de justificação, para que a construção do sentido e, portanto, da coerência não venham a ser prejudicadas".

\section{Contexto de produção da carta aberta em uma pesquisa de doutorado}

Selecionamos, como corpus de análise para este artigo, duas versões de uma carta aberta produzida pelo PD16, durante a pesquisa de doutorado de uma das autoras deste artigo, cuja geração de dados foi realizada entre os meses de agosto a dezembro de 2018. Tanto a produção em questão, constituída de três versões, como as produções de um artigo de opinião e duas redações do Exame Nacional do Ensino Médio (ENEM), também compostas por três versões, foram escritas por integrantes de uma turma de terceiro ano de Ensino Médio de uma escola da rede pública estadual de ensino da cidade de Santa Maria, RS.

Ademais, salientamos que a base metodológica utilizada foi a pesquisa-ação, consoante Burns (1999) e Thiollent (2011), a qual se trata de uma metodologia de pesquisa que prevê que pesquisador e participante de pesquisa atuem de modo colaborativo e corresponsável. 
Dessa forma, após se inserir em um grupo social específico - no caso, a referida turma - pesquisador e participantes de pesquisa passam a atuar de modo corresponsável e colaborativo, a fim de contemplar um objetivo comum.

O objetivo da pesquisa em pauta era o desenvolvimento da habilidade de escrita argumentativa e, para isso, a pesquisadora utilizou a base teórica da Linguística do Texto (LT), com foco no trabalho com informatividade, em consonância com as disposições de Beaugrande e Dressler (1981), Costa Val (1999) e Koch e Elias (2014), principalmente. Desse modo, repousando nesse alicerce teórico, estratégias argumentativas foram elaboradas para o trabalho com produções textuais do campo argumentativo.

Convém pontuar que a referida pesquisa não explorou juntamente com os participantes a progressão tópica, haja vista que o foco era o critério de informatividade. Nosso foco, aqui, volta-se a um novo e diferente estudo sobre esse texto (já findado) do estudante da escola básica, sob a olhar da progressão tópica.

A carta aberta, último gênero trabalhado com os estudantes, foi explorada no mês de dezembro. Para dinamizar esse gênero, a pesquisadora selecionou um tema voltado ao sentimento de solidariedade, que recebe ênfase em algumas datas comemorativas, como o Natal: a doação de sangue.
Nesse cenário, após o trabalho com o gênero, foram apresentados, aos estudantes, quatro textos-base sobre o tema (dispostos em uma página) e o seguinte comando de produção textual: "E você jovem, estudante da E.E.E.B Prof. ${ }^{a}$ Margarida Lopes, o que pensa sobre a doação de sangue? Escreva uma CARTA ABERTA aos jovens santa-marienses manifestando a importância ou não de se tornarem doadores de sangue. Seu texto deve ter, no mínimo, 20 e, no máximo, 30 linhas. Não esqueça que o gênero em pauta exige a marcação do remetente"1. A partir desse comando e da leitura dos textos-base, PD16 desenvolveu sua carta aberta, cujas versões selecionadas apresentamos na subseção posterior.

\section{Corpus de análise}

Nosso corpus de análise é constituído por Versão 1 e Versão 3 de uma carta aberta produzida pelo PD16 ${ }^{2}$. Tal carta contemplou, no contexto de produção de uma pesquisa de doutorado ${ }^{3}$, primeira escrita e duas reescritas. Julgamos que, ao olhar para o momento inicial e final do processo de escrita, é possível observar se ocorre ou não progresso na construção argumentativa da produção do estudante. Na sequência, nas Figuras 2 e 3 , expomos tais versões. 
Figura 2 - Versão 1

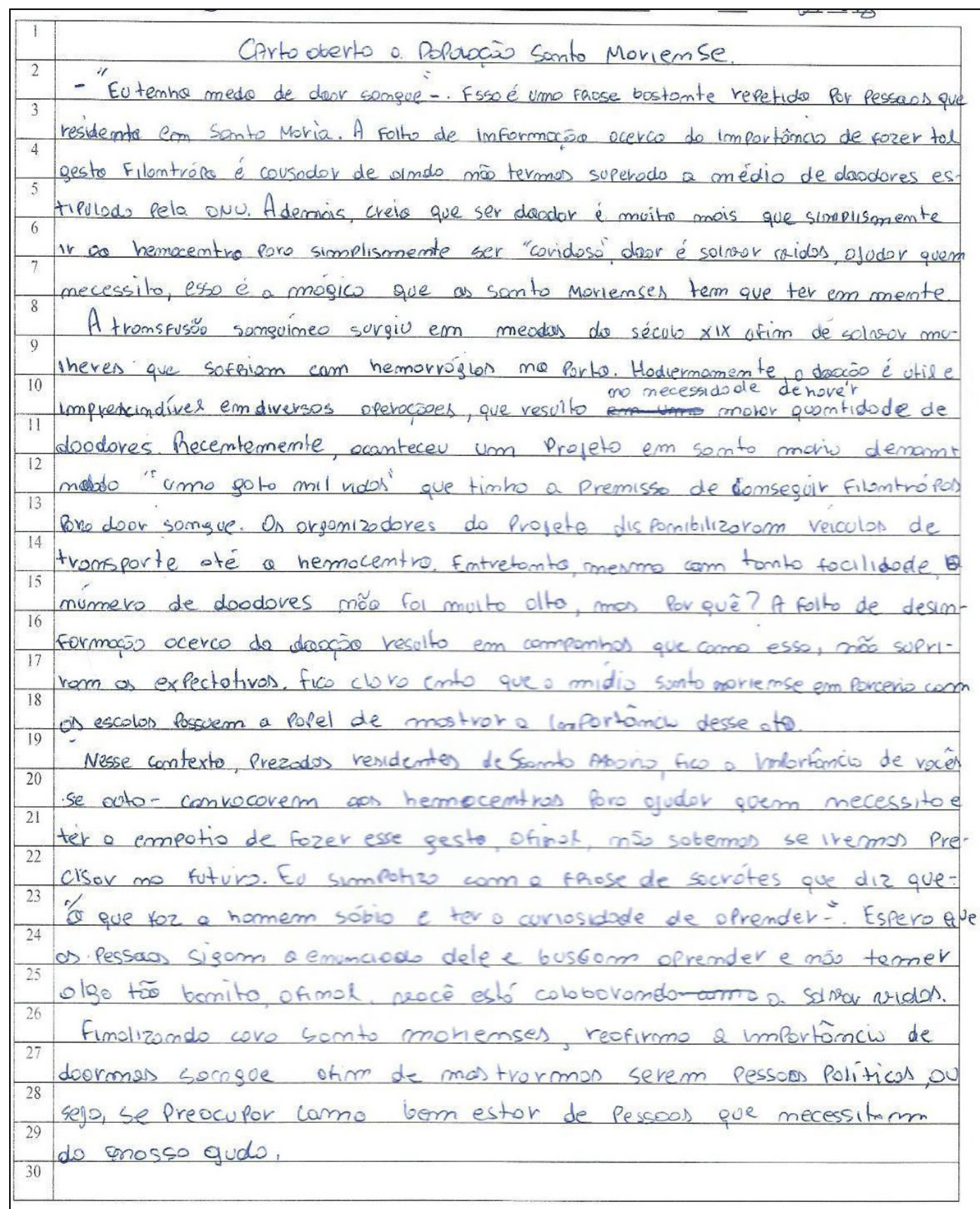

Fonte: PD16 (2018). 
Figura 3 - Versão 3

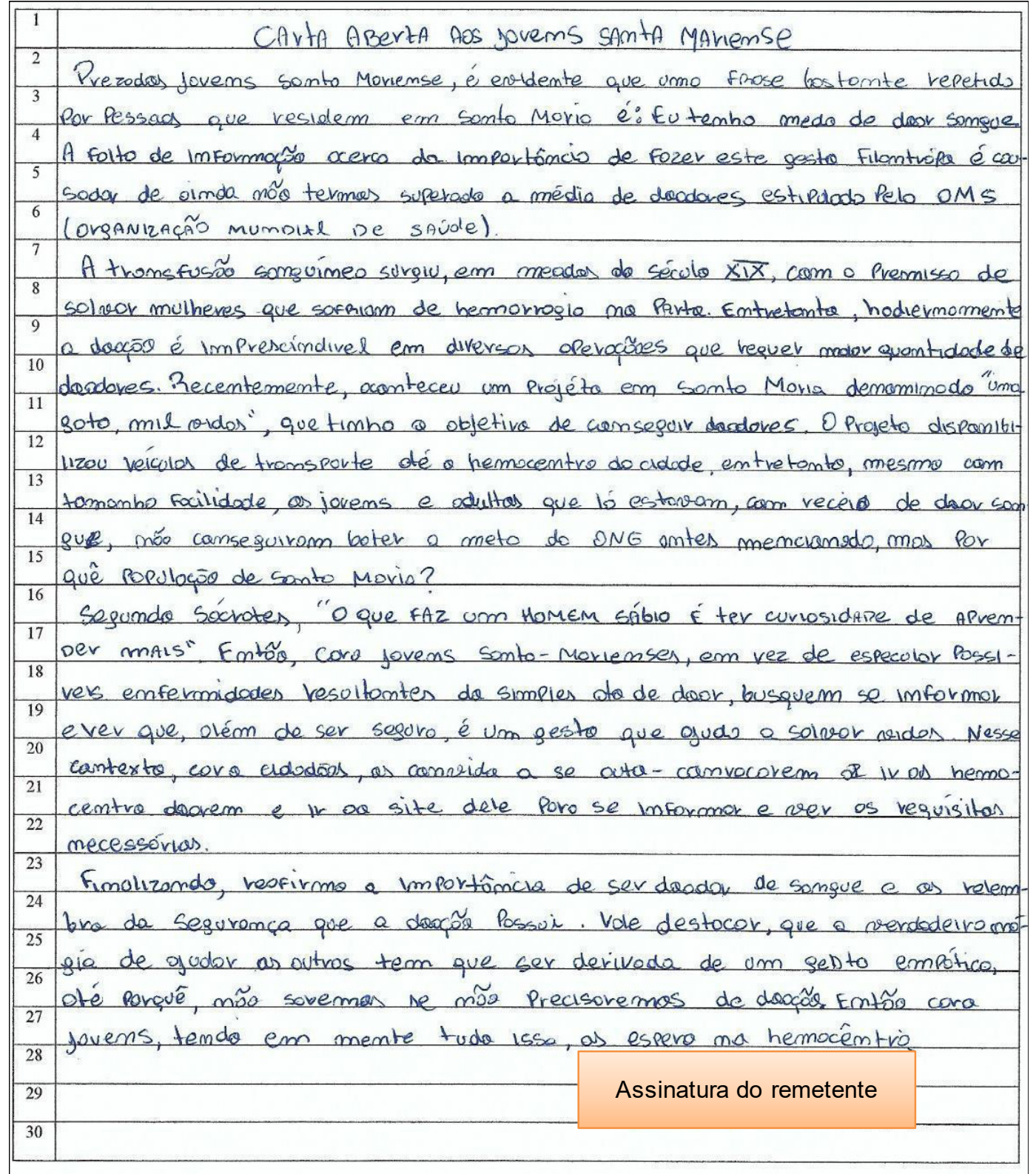

Fonte: PD16 (2018). 


\section{Passos de análise}

Para realizar a análise deste estudo, organizamos dois passos: $1^{\circ}$ ) estrutura composicional do gênero carta aberta; $2^{\circ}$ ) disposição das pirâmides tópicas. Tendo em vista a importância do conhecimento das especificidades da carta aberta, o primeiro passo busca verificar o progresso do estudante em relação à apropriação desse gênero, isto é, se a produção analisada respeita a estrutura-base (vide Quadro 2).

Realizada essa visão holística, o segundo passo está centrado na progressão tópica, em que elaboramos duas pirâmides, uma para cada versão escrita analisada. Destacamos que, na posição de pesquisadoras-professoras, consideramos relevante investir nesse fenômeno linguístico, tendo em mente que pode contribuir com o processo de escrita argumentativa.

Além disso, as pirâmides tópicas, por assumirem um caráter mais visual, facilitam a identificação da construção do texto em relação à continuidade e à descontinuidade dos tópicos. Dessa maneira, o professor e o estudante parceiros no processo de escrita - podem potencializar a construção/utilização de estratégias argumentativas por meio do desenvolvimento dos tópicos e minimizar as digressões, interrupções e descontinuidades. A seguir, no Quadro
4, compilamos esses passos de análise e suas respectivas categorias.

Quadro 4 - Passos e categorias de análise

\begin{tabular}{|c|c|c|}
\hline \multicolumn{2}{|r|}{ Passos de análise } & Categorias \\
\hline \multirow{6}{*}{$1^{\circ}$} & \multirow{6}{*}{$\begin{array}{l}\text { Estrutura com- } \\
\text { posicional do gê- } \\
\text { nero carta aberta }\end{array}$} & $\begin{array}{l}\text { Título com gênero e destina- } \\
\text { tário(s). }\end{array}$ \\
\hline & & $\begin{array}{l}\text { Apresentação de problema de } \\
\text { interesse coletivo. }\end{array}$ \\
\hline & & $\begin{array}{l}\text { Utilização de argumentos para } \\
\text { defender o ponto de vista, por } \\
\text { meio de estratégias argumen- } \\
\text { tativas. }\end{array}$ \\
\hline & & $\begin{array}{l}\text { Apresentação de conclusão } \\
\text { sobre a discussão na tentativa } \\
\text { de convencer o destinatário. }\end{array}$ \\
\hline & & Apresentação do remetente. \\
\hline & & $\begin{array}{l}\text { Explicitação do destinatário ao } \\
\text { longo do texto. }\end{array}$ \\
\hline \multirow{2}{*}{$2^{\circ}$} & \multirow{2}{*}{$\begin{array}{l}\text { Disposição das } \\
\text { pirâmides tópicas }\end{array}$} & Supertópico. \\
\hline & & Subtópico. \\
\hline
\end{tabular}

Fonte: Organizado pelas autoras

\section{Estrutura composicional do gênero carta aberta}

Levando em conta o comando de produção textual apresentado aos estudantes, elaboramos o Quadro 5 para elucidar os progressos em relação aos elementos constitutivos do gênero. Destarte, utilizamos: "S" ( $\operatorname{sim}$ ) para apontar que o item foi contemplado satisfatoriamente; "EP" (em parte) para sinalizar que o item se revela de modo parcial; e "N" (não) para indicar que o item não consta no texto. 
Quadro 5: Quadro comparativo das versões 1 e 3 referentes às categorias de análise da carta aberta

\begin{tabular}{|l|c|c|}
\hline \multicolumn{1}{|c|}{ Categorias de análise } & \multicolumn{2}{c|}{ Versão } \\
\cline { 2 - 3 } & 1 & 3 \\
\hline Título com gênero e destinatário(s). & EP & S \\
\hline Apresentação de problema de interesse coletivo. & $\mathrm{S}$ & $\mathrm{S}$ \\
\hline $\begin{array}{l}\text { Utilização de argumentos para defender o ponto de vista por meio de estratégias } \\
\text { argumentativas. }\end{array}$ & $\mathrm{S}$ \\
\hline Apresentação de conclusão sobre a discussão na tentativa de convencer o destinatário. & $\mathrm{EP}$ & $\mathrm{S}$ \\
\hline Apresentação do remetente. & $\mathrm{N}$ & $\mathrm{S}$ \\
\hline Explicitação do destinatário ao longo do texto. & EP & $\mathrm{S}$ \\
\hline
\end{tabular}

Fonte: Elaborado pelas autoras.

Nesse quadro, podemos identificar que, na Versão 3, em comparação à Versão 1, PD16 revela avanços em relação às categorias analisadas. No que concerne ao título com gênero e destinatário(s), compreendemos que, em ambas as versões da carta, na linha 1, o autor menciona o gênero "carta aberta". No entanto, a respeito do destinatário, na primeira escrita o estudante se dirige "a população santa", ao passo que, na segunda, ele restringe a carta "aos jovens santa mariense" ${ }^{4}$. Dessa forma, contempla apenas, na última versão, o que foi solicitado no comando da produção.

Quanto à apresentação de problema de interesse coletivo, na linha 5, PD16 já o mencionava na primeira versão, mantendo-o na linha 6 da versão final: "não termos superado a média de doadores estipulada pela OMS”. De igual modo, no que concerne à utilização de argumentos para defender o ponto de vista, por meio de estratégias argumentativas ${ }^{5}$, o autor apresenta-as nas duas versões, empregando informações a partir de alusão histórica - como pode-se observar no seguinte trecho, nas linhas 7 e 8 , da última versão: "A transfusão sanguínea surgiu, em meados do século XIX, com a premissa de salvar mulheres que sofriam de hemorragia no parto" - e a partir de ideal filosófico, como a menção a Sócrates, presente na Versão 1 (linha 22) e na Versão 3 (linha 16).

Por seu turno, a apresentação de conclusão sobre a discussão na tentativa de convencer o destinatário se manifesta parcialmente na primeira escrita, pois PD16, ao enfocar - linhas 26, 27 e 28 -, na "importância de doarmos sangue afim de mostrarmos serem pessoas políticas, ou seja, se preocupar com o bem estar de pessoas que necessitam", desconsidera a questão da "falta de informação", presente nas linhas 15 e 16 , a qual, em nossa ótica, constitui a ideia central defendida pelo autor. Em contrapartida, na última escrita, ao relembrar os leitores, na linha 24 , sobre a "segurança que a doação possui", ele retoma indiretamente a pertinência de seu público-alvo se informar 
acerca da doação de sangue ser um ato seguro. Ademais, busca convencer os interlocutores a doar sangue ao apelar para o emocional: "vale destacar, que a verdadeira magia de ajudar os outros tem que ser derivada de um gesto empático, até porquê, não sabemos se não precisaremos de doações" (linhas $24,25 \mathrm{e}$ 26), conferindo um caráter reflexivo à defesa. Para finalizar, convida, nas linhas 26 e 27, seu destinatário a comparecer ao hemocentro de Santa Maria: "então caros jovens, tendo em mente tudo isso, os espero no hemocêntro".

Já a apresentação do remetente não consta na Versão 1, apenas na Versão 3 - linha 29. Por fim, a explicitação do destinatário ao longo do texto, está, em nossa compreensão, atrelada ao título - "Carta aberta a população santa mariense" (Versão 1) e "Carta aberta aos jovens santa mariense" (Versão 3), visto que o comando da produção delineava os "jovens santa-marienses" como destinatários.

Observamos que, na primeira versão, PD16 se destina, na linha 19, aos "prezados residentes de Santa Maria" e, na linha 26, aos "caro santa marienses", não se adequando ao destinatário que o comando solicitava. Diferentemente disso, na última escrita, menciona os “jovens santa marienses" (linhas 2 e 17) e os "caro jovens", (linhas 26 e 27) - destinatário solicitado no comando da produção -, à exceção dos segmentos em que direciona uma pergunta à "população de Santa Maria”, na linha 15, e "aos caros cidadãos", na linha 20 .

\section{Disposição das pirâmides tópicas}

Com base em Koch (2014) e Jubran (2015), organizamos duas pirâmides tópicas - uma para cada versão analisada (1 e 3) - da carta aberta produzida pelo PD16. Para isso, baseamo-nos em um esquema elaborado por Machado (2018), conforme expomos na Figura 1, que consta na subseção intitulada Progressão tópica. A seguir, dispomos a Figura 4 relativa à progressão tópica da Versão 1.

Figura 4 - Pirâmide tópica da Versão 1

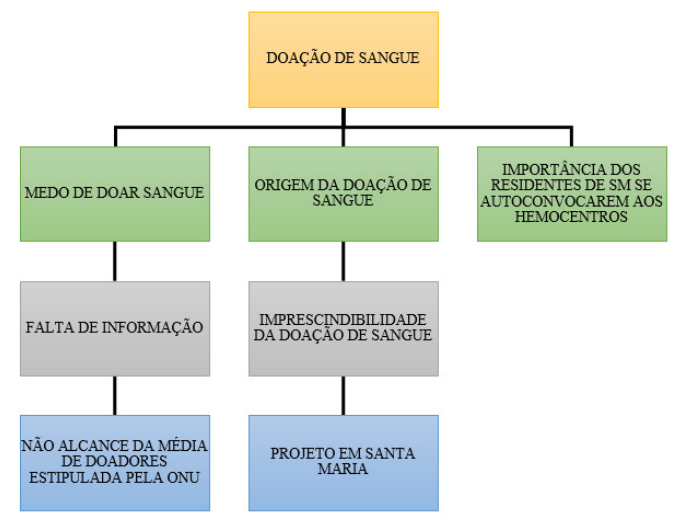

Fonte: Elaborado pelas autoras.

Na Figura 4, temos quatro níveis hierárquicos. No primeiro deles, há o supertópico "doação de sangue", assim caracterizado por ser o tema da produção textual. No segundo, constam três sub- 
tópicos desse supertópico, que representam o que é discutido nos parágrafos de introdução e desenvolvimento do texto. Esses, por sua vez, são supertópicos do terceiro nível que é supertópico do quarto. Dando seguimento, passamos à Figura 5, que aborda a progressão tópica na Versão 3.

Figura 5 - Pirâmide tópica da Versão 3

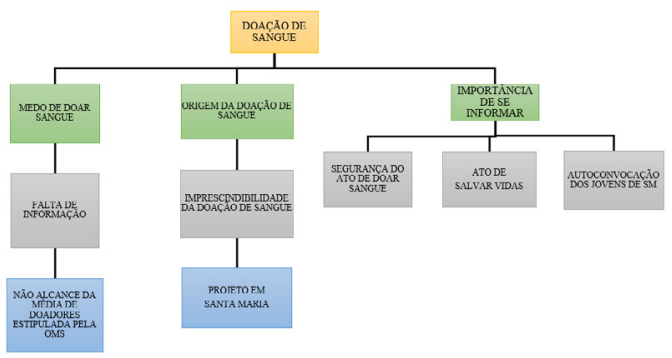

Fonte: Elaborado pelas autoras.

Em sua instância, a pirâmide tópica da Versão 3, comparada à Versão 1 , apresenta a mesma quantidade de níveis hierárquicos. Entretanto, no que tange ao terceiro nível - parágrafos de desenvolvimento -, observamos que o supertópico "importância de se informar" - segundo nível - é explorado com a inserção de três subtópicos. Com isso, é possível visualizar como o texto de PD16 foi organizado em termos de progressão tópica, ou seja, de que maneira o tema principal foi desenvolvido ao longo dos movimentos da produção textual em análise.

\section{Discussão sobre os dois objetos de análise}

Retomando o exposto nas duas subseções anteriores, notamos que, quanto à constituição do gênero em foco, PD16 revelou avanços, na Versão 3, de modo a demonstrar que sua produção final se efetiva enquanto carta aberta. Em relação às pirâmides tópicas, observamos que há hierarquia e linearidade, além de que existem alterações observadas nos subtópicos do terceiro nível referente ao parágrafo 3 de ambas as versões.

Todavia, nas duas versões analisadas, embora seja possível organizar essas pirâmides nesses planos - hierárquico e linear -, quando focalizamos na propriedade tópica da organicidade, podemos atentar que, a partir do supertópico "doação de sangue", PD16 desenvolve o subtópico "medo de doar sangue", o qual se subdivide no subtópico "falta de informação", que, por sua vez, torna-se supertópico de "não alcance da média de doadores". Sendo assim, observamos que apenas no quarto nível do plano hierárquico consta o problema de interesse coletivo. Esse elemento constitutivo do gênero assume caráter mais particularizado em relação ao supertópico "doação de sangue", de forma que o foco recai sobre o sentimento de medo de doar sangue. 
Os segundo e terceiro parágrafos, das duas versões discutidas, são referentes à utilização de argumentos na defesa do ponto de vista para convencer o destinatário a doar sangue. No segundo parágrafo, o qual configura-se, na pirâmide tópica, de maneira igual nas duas versões, PD16 apresenta, no segundo nível hierárquico, o tópico "origem da doação de sangue", desenvolvido nos subtópicos "imprescindibilidade da doação" e "projeto em Santa Maria" - terceiro e quarto níveis, respectivamente.

Já no que tange ao terceiro parágrafo, observamos que há alterações na configuração da pirâmide tópica, uma vez que, na primeira escrita, há somente o segundo nível do plano hierárquico, constituído pelo subtópico “importância dos residentes de Santa Maria se autoconvocarem aos hemocentros". Na reescrita, por seu turno, entendemos que PD16 não apenas modifica o tópico do segundo nível, como também alcança um nível a mais na hierarquia. Desse modo, o terceiro parágrafo da pirâmide tópica, referente à Versão 3, constitui-se do tópico "importância de se informar", subdividido nos subtópicos "segurança do ato de doar sangue", "ato de salvar vidas" e "autoconvocação dos jovens de SM".

Considerando a relação dos tópicos com o gênero carta aberta, podemos notar que, nos parágrafos de desenvolvimento, PD16 resgata, indiretamente, o tópico "falta de informação", apresentado na introdução, pois traz informações para suprir essa falta, a fim de apresentar ao seu interlocutor a origem da doação de sangue, bem como da existência de um projeto desenvolvido na cidade que visa à adesão de doadores. No terceiro parágrafo da Versão 3, o estudante investe no tópico "importância de se informar", sugerindo ao interlocutor que busque outras informações, como, por exemplo, em sites, para observar que o ato de doar sangue não somente é seguro, como também proporciona salvar vidas.

Como podemos notar nas pirâmides tópicas, temos três tópicos no segundo nível, em que cada um advém dos parágrafos de introdução e dos dois parágrafos de desenvolvimento, respectivamente. Não consta um novo tópico no parágrafo de conclusão, o que, em nosso entendimento, está atrelado à natureza constitutiva do gênero carta aberta. Ele não requer a menção de novos tópicos, mas sim a retomada dos tópicos já discutidos na tentativa de convencer o interlocutor a aderir ao ponto de vista defendido.

Diante disso, a partir do nosso percurso analítico, compreendemos que PD16, para explorar o problema mencionado na introdução de sua carta aberta - "não alcance da média de doadores" (linhas 4 e 5 - Versões 1 e 3) - utilizou, no desenvolvimento, estratégias argumentativas - informação a partir de alusão histórica e informação a partir de ideal filosófico. Em termos de progressão tópica, o texto 
apresenta tópicos, que, no plano hierárquico, estão subdivididos em supertópicos e subtópicos. Por exemplo, na versão final, o supertópico "importância de se informar" é desenvolvido por meio da apresentação dos benefícios, tanto para quem doa: subtópico "segurança do ato de doar sangue", como para quem recebe: subtópico "ato de salvar vidas".

Além do mais, evidenciamos que esses tópicos, embora apresentados, foram parcialmente desenvolvidos, o que podemos observar no segundo parágrafo de ambas as versões. Diferentemente do exemplo anterior, no caso do supertópico “origem da doação de sangue", há uma quebra de continuidade no quadro tópico, o que ocorre com a inserção do subtópico "imprescindibilidade da doação de sangue". Por conseguinte, isso restringe a construção argumentativa da carta aberta analisada, demonstrando que o trabalho com a progressão tópica é necessário e pode contribuir no processo de produção textual argumentativa.

\section{Conclusão}

Ao longo deste artigo, buscamos refletir sobre como o trabalho com a composição do gênero carta aberta e com a progressão tópica pode contribuir para práticas de produção textual no âmbito escolar. Fizemos isso utilizando, como corpus de análise, duas versões (1 e 3) de uma carta aberta produzida por um estudante de Ensino Médio de uma escola pública.

Para fundamentarmos teoricamente nossa análise, apoiamo-nos em estudos de Dolz e Schneuwly (2004), Costa (2014), Koch (2014), Jubran (2015) e Machado (2018), referentes ao gênero carta aberta e à progressão tópica. A partir deles, elaboramos dois passos de análise: estrutura composicional do gênero carta aberta e disposição das pirâmides tópicas, os quais culminaram na discussão sobre os dois objetos de análise.

$\mathrm{Na}$ análise propriamente dita, constatamos que, em relação à estrutura composicional do gênero em pauta, a Versão 3, comparada à Versão 1 , apresenta avanços, pois atende de modo mais satisfatório os elementos constitutivos da carta aberta. Quanto à disposição das pirâmides tópicas, percebemos que a Versão 3, diferentemente da Versão 1 , apresentou o acréscimo de três subtópicos no segundo nível do terceiro parágrafo. Contudo, conforme destacamos em nossa discussão, há uma quebra na continuidade do quadro tópico que envolve os níveis 2 e 3 , o que compromete, de modo parcial, a argumentatividade do texto analisado.

Ante o exposto, constatamos que, apesar da estrutura do gênero ser contemplada, adequadamente, a partir de um processo de escrita, os tópicos podem ser desenvolvidos de maneira parcial, de 
modo que as estratégias argumentativas acabem não sendo suficientemente exploradas. Tal constatação reforça a necessidade do uso de um recurso que atue no desenvolvimento das ideias e na aprimoração da argumentação no texto. Em razão disso, consideramos fundamental o trabalho com a progressão tópica para o avanço da escrita argumentativa dos estudantes no que diz respeito à continuidade e à coerência do texto.

\section{Open letter at school: a look from genre composition and the topical progression}

\section{Abstract}

In this paper, we reflect about how the work with composition of the genre open letter and with the topical progression can contribute to textual production practices in the school because we consider this articulation as one more possibility to subsidize the process of argumentative writing. As a corpus of analysis, we select two versions of an open letter, which was produced by a third-grade High School student. For this, we established two analytical steps: $1^{\circ}$ ) compositional structure of the genre open letter, $2^{\circ}$ ) arrangement of the topical pyramids. As a result, we observed that, in relation to structure, there were advances with regard to the title and signature of the sender in the last version analyzed. As for the topical progression, we found that the topics were partially developed, restricting the argumentative construction. Thus, we expect that this reflection can support pedagogical practices and assist in the advancement of school writing, so that the argumentative strategies are sufficiently explored.

Keywords: Open letter; textual production; topical progression

\section{Notas}

1 Presente na sequência didática 05 (SD5), Arnemann (2020, p. 399).

2 Cabe destacar que PD16 participou - conforme informou em uma das aulas dedicadas ao estudo e respectiva escrita da carta aberta - do Projeto "Uma gota, mil vidas", o qual foi promovido pelo Instituto Estadual de Educação Olavo Bilac em parceria com outras instituições, conforme pode ser conferido no seguinte link: http://centralsul.org/2018/instituto-olavo-bilac-promove-acao-uma-gota-mil-vidas/.

3 O processo de escrita que resultou nas três versões mencionadas foi dinamizado por meio de uma sequência didática (SD 5), a qual pode ser consultada em Arnemann (2020, p. 389-401).

4 Os participantes de pesquisa trabalharam por meio de um quadro com dez estratégias argumentativas (ARNEMANN, 2020, p. 401), dentre elas, informação a partir de alusão histórica e informação a partir de ideal filosófico - mediante citação de autoridade.

\section{Referências}

ARNEMANN, A. R. Informatividade na sala de aula: o emprego de informações na construção de argumentos. 2020, 438 p. (Doutorado em Estudos Linguísticos) - Universidade Federal de Santa Maria, RS, 2020.

BAKHTIN, M. Os gêneros do discurso. In: Estética da criação verbal. 6 ed. São Paulo: Martins Fontes, 2011.

BAKHTIN, M.. Marxismo e Filosofia da linguagem: Problemas Fundamentais do Método Sociológico na Ciência da Linguagem. 
16 ed. Tradução de Michel Lahud e Yara Frateschi Vieira. São Paulo: Hucitec, 2014.

BEAUGRANDE, R. de.; DRESSLER, W. Introduction to Text Linguistics. New York: Longman, 1981.

BRASIL. Ministério da Educação. Base Nacional Comum Curricular. Brasília: MEC, 2018. Disponível em: <http://basenacionalcomum.mec.gov.br>. Acesso em: 05 fev. 2020.

BURNS, A. Collaborative Action Research for English Language Teachers. Cambridge University Press, 1999.

COSTA, S. R. Dicionário de gêneros textuais. Belo Horizonte: Autêntica Editora, 2014.

DOLZ, J.; SCHNEUWLY, B. Gêneros e progressão em expressão oral e escrita - elementos para reflexões sobre uma experiência suíça (francófona). In: DOLZ, J.; SCHNEUWLY, B. (Org.). Gêneros orais e escritos na escola. Campinas, SP: Mercado de Letras, 2004. p. $35-60$.

GÊNEROS TEXTUAIS na prova de redação - Videoaula sobre Carta Aberta. Produção de Cristiane COPERVES. Brasil: COPERVES (59 min), 2014. Disponível em: < https:// www.youtube.com/watch?v=Uxcz3-wyyb4 >. Acesso em: 15 mai. 2018.

JUBRAN, C. S. (Org.). A construção do texto falado. São Paulo: Contexto, 2015.

KOCH, I. G. V. As tramas do texto. São Paulo: Contexto, 2014.

. Desvendando os segredos do texto. São Paulo: Contexto, 2015.

KOCH, I. G. V.; ELIAS, V. M. Ler e escrever: estratégias de produção textual. 2 ed. 2 reimp. São Paulo: Contexto, 2014.

MACHADO, L. N. Progressão tópica em textos orais de alunos do ensino médio: um estudo a partir da Linguística do Texto e da Pesquisa-ação. Dissertação (mestrado) -Universidade Federal de Santa Maria, Centro de Artes e Letras, Programa de Pós-Graduação em Letras, RS, 2018.
THIOLLENT, M. Metodologia da Pesquisa-ação. 18 ed. São Paulo: Cortez, 2011.

UFSM. Manual do candidato. COPERVES: Santa Maria, 2016.

VAL, M. da G. C. Redação e textualidade. 2 ed. São Paulo: Martins Fontes, 1999. 